\title{
EFFECT OF CUTTING PARAMETERS ON DRY TURNING OF AUSTENITIC STAINLESS STEEL (316L)
}

\author{
ABY M PHILIP ${ }^{1} \&$ DR. KALYAN CHAKRABORTY ${ }^{2}$ \\ ${ }^{I}$ Master of Technology, Department of Mechanical Engineering National Institute of Technology Silchar, Assam \\ ${ }^{2}$ Associate Professor, Department of Mechanical Engineering National Institute of Technology Silchar, Assam
}

\begin{abstract}
Austenitic Stainless steel is one of the widely used stainless steel, SS 316 and SS316L are two different grades of which SS 316L has more corrosion resistant property and is weldable. Austenitic stainless steel (316L) is difficult to machine because it gets work hardened easily, its low thermal conductivity, high ductility, high strength also makes it machinability difficult. In this study theoretical analysis is done to find which cutting parameter has more effect on machining, it is done by using Taguchi and Fuzzy Inference System (FIS) from MATLAB. Data for theoretical analysis was collected from a combination of experiments which has a central composite design. The second order models were established for chip reduction coefficient and MRR. Subsequently second order models are used for converting those data to the data which is compatible for Taguchi analysis. The effect of various machining parameters on machining responses can be studied from the established model. The output from the simulation was generated as Multi Performance Characteristic Index (MPCI). Finding the position of various machining parameters was the next step of analysis. The rank with respect to various machining parameters cutting speed, feed, and depth of cut was established.

KEYWORDS: Metal Cutting, Machining, Chip Thickness, Work Hardening, Machinability.
\end{abstract}

Received: Jun 08, 2020; Accepted: Jun 28, 2020; Published: Aug 29, 2020; Paper Id.: IJMPERDJUN2020942

\section{INTRODUCTION}

Most parts of the world like Europe and Ushas instituted laws and regulations that appreciably affect the formulation of metal cutting fluids [1]. Industries using these fluids are relentlessly searching for better performing cutting fluids formulated from environmentally friendly materials. Also, most Governments, Industries and Employee Unions implement movements for a healthy and safe work environment, as well as disposal aspects influencing the global environment. These movements have already affected the formulation of cutting fluids in Europe and the US as follows: the removal of nitrite from cutting fluid composition and the replacement of di-ethanolamine short chained chlorinated paraffin $[1,2]$.

Austenitic stainless steel is one of the most widely used stainless steel because of its high corrosion resistance and high strength. Austenite phase is metastable, because of the presence of alloying element nickel, magnesium and nitrogen helps to maintain austenitic structure at all temperature from cryogenic to melting point. Austenitic stainless steel cannot be heat treated because it must maintain the same microstructure. It can be hardened by cold working only. Austenitic stainless steel is paramagnetic. Austenitic stainless steel (316L) has low carbon percentage when compared to grade SS 316, this helps to avoid corrosion of welding due to high temperature involvement and prevent sensitization. 
Austenitic stainless steel is difficult to machine because of its work hardening tendency, low thermal conductivity and high built up edge formation. In this study the effect of different cutting parameters i.e. cutting velocity, feed and depth of cut on dry turning of austenitic stainless steel (316L) is analysed by using Taguchi and Fuzzy Inference system, based on Chip reduction coefficient and Material Removal Rate (MRR). From the MPCI value rank of each cutting parameters affecting the machining can be obtained

\section{PROPOSED METHODOLOGY}

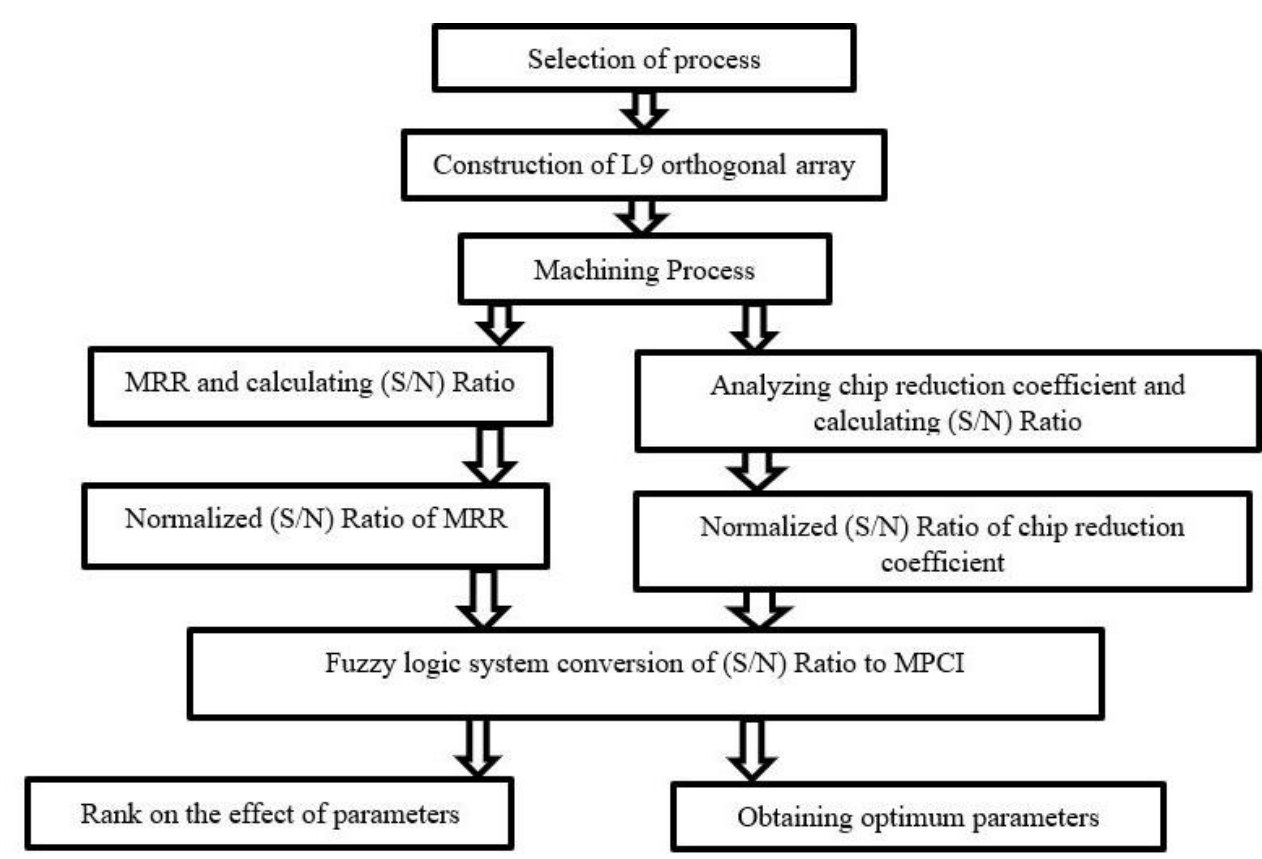

Fig 1. Methodology of MPCI

Since austenitic stainless steel can be considered as difficult to machine materials, therefore the present task is undertaken to study on the machining aspects of the material. Tungaloy made tool is used. Tool holder ASBNR $25 * 25 \mathrm{M} 12$ A and carbide insert SNMG 120404 TM T9125 were collected. After machining in predetermined parameters, the calculated values of chip reduction coefficient and MRR was taken and a second order equation was formed by using analysis of variance (ANOVA). Based on the machining parameters orthogonal array was selected for chip reduction coefficients and MRR. S/N ratios were calculated by using Taguchi analysis by considering lower the chip reduction coefficient (best) and higher the MRR (best). From the S/N ratios, normalized values were found and with the normalized values MPCI values were obtained through MATLAB software, using FIS.

\section{EXPERIMENTATION}

The workpiece is of dimension $300 \mathrm{~mm}$ length and $60 \mathrm{~mm}$ diameter. Machining is performed and experimental data were collected. Central composite design of input parameters was followed for machining of workpiece. 24 different combination of the machining parameters (Table II) were used for turning of workpiece. The formed data were arranged in such a way to form a central composite design consisting of $2^{3}$ factorials with centre point replicated 4 times plus a twice replicated star design. The chip obtained for the 24 experiments were collected and the thickness of chip was calculated using relation between chip length and weight of the chip. Calculation of chip reduction coefficient and MRR will be done using 
corresponding equations. Turning operation is carried out in central lathe having maximum speed $1000 \mathrm{rpm}$ and minimum speed $45 \mathrm{rpm}$ and feed ranges between $0.06 \mathrm{~mm} / \mathrm{rev}$ to $1.72 \mathrm{~mm} / \mathrm{rev}$.

Table 1: Chemical Composition of Austenitic Stainless Steel (316L)

\begin{tabular}{|c|c|c|c|c|c|c|c|c|}
\hline $\mathbf{C} \%$ & $\mathbf{M n} \%$ & $\mathbf{S i} \%$ & $\mathbf{P \%}$ & $\mathbf{C r} \%$ & $\mathbf{N i} \%$ & $\mathbf{M o \%}$ & $\mathbf{S \%}$ & $\mathbf{F e}$ \\
\hline 0.010 & 1.623 & 0.321 & 0.010 & 16.122 & 10.147 & 2.123 & 0.005 & Balanced \\
\hline
\end{tabular}

Table 2: Parameters used for Machining

\begin{tabular}{|l|c|c|c|c|c|}
\hline \multicolumn{1}{|c|}{ Coding } & $-\sqrt{\mathbf{2}}$ & $\mathbf{- 1}$ & $\mathbf{0}$ & $\mathbf{1}$ & $\sqrt{\mathbf{2}}$ \\
\hline Speed $(\mathrm{m} / \mathrm{min})$ & 10.23 & 14.24 & 31.65 & 70.34 & 97.9 \\
\hline Feed $(\mathrm{mm} / \mathrm{rev})$ & 0.01 & 0.11 & 0.14 & 0.18 & 0.20 \\
\hline DOC $(\mathrm{mm})$ & 0.56 & 0.67 & 1 & 1.5 & 1.77 \\
\hline
\end{tabular}

Chip thickness $t_{2}=\frac{W}{\rho w l}$

Where, $t_{2}=$ Chip thickness

$W=$ Weight of chip in grams

$\rho=\quad$ Density of chip in $\mathrm{g} / \mathrm{cm} 3$

$w=\quad$ Width of chip in $\mathrm{cm}$

$l=$ Average length of the chip in $\mathrm{cm}$

Where, $d=$ Depth of cut in $\mathrm{mm}$

$$
\text { Width of chip } w=\frac{d}{\cos (90-\phi)}
$$

$\phi=$ Principle Cutting-edge angle (in degree)

$\rho=\quad$ Density of austenitic stainless steel, $8 \mathrm{~g} / \mathrm{cm} 3$

Uncut chip thickness $t_{l}$,

$$
t_{1}=f^{*} \sin \phi
$$

Where, $f=$ Feed in $\mathrm{mm}$

$$
\phi=\quad \text { Principal Cutting-edge angle (in degree) }
$$

Chip reduction coefficient $\zeta$,

$$
\zeta=\frac{t_{2}}{t_{1}}
$$


Table III Calculated output values from experiment

\begin{tabular}{|c|c|c|c|c|c|c|c|c|c|}
\hline \multirow{2}{*}{$\begin{array}{c}\text { Sr } \\
\text { No. } \\
1\end{array}$} & \multicolumn{3}{|c|}{ Assigned Codes } & $\begin{array}{l}\text { Weight of } \\
\text { chip(W) } \\
(\text { gms })\end{array}$ & $\begin{array}{l}\text { Length of } \\
\text { chip(L) } \\
(\mathrm{mm})\end{array}$ & $\begin{array}{l}\text { Width of } \\
\text { chip(w) } \\
(\mathbf{m m})\end{array}$ & $\begin{array}{c}\text { Chip } \\
\text { thickness }\left(\mathrm{t}_{2}\right) \\
(\mathrm{mm})\end{array}$ & $\begin{array}{c}\text { MRR } \\
\left(\mathrm{mm}^{3} / \mathrm{s}\right)\end{array}$ & $\begin{array}{c}\text { Chip } \\
\text { reduction } \\
\text { coefficient }(\zeta)\end{array}$ \\
\hline & 1 & 1 & 1 & 0.340 & 8.3 & 1.552 & 0.330 & 316.51 & 1.898 \\
\hline 2 & 1 & 1 & -1 & 0.033 & 1.4 & 0.689 & 0.422 & 140.53 & 2.428 \\
\hline 3 & 1 & -1 & 1 & 0.539 & 21.3 & 1.552 & 0.203 & 189.90 & 1.952 \\
\hline 4 & 1 & -1 & -1 & 0.139 & 11.2 & 0.689 & 0.225 & 84.31 & 2.166 \\
\hline 5 & -1 & 1 & 1 & 1.031 & 21.3 & 1.555 & 0.389 & 64.06 & 2.240 \\
\hline 6 & -1 & 1 & -1 & 0.083 & 7.1 & 0.689 & 0.212 & 28.44 & 1.220 \\
\hline 7 & -1 & -1 & 1 & 0.210 & 8.9 & 1.552 & 0.190 & 38.44 & 1.821 \\
\hline 8 & -1 & -1 & -1 & 0.181 & 13.3 & 0.689 & 0.246 & 17.06 & 2.359 \\
\hline 9 & $\sqrt{2}$ & 0 & 0 & 0.394 & 20 & 1.035 & 0.237 & 228.43 & 1.759 \\
\hline 10 & $-\sqrt{2}$ & 0 & 0 & 0.411 & 14 & 1.035 & 0.354 & 23.87 & 2.620 \\
\hline 11 & 0 & $\sqrt{2}$ & 0 & 0.709 & 16.2 & 1.035 & 0.528 & 104.97 & 2.750 \\
\hline 12 & 0 & $-\sqrt{2}$ & 0 & 0.269 & 13.9 & 1.035 & 0.234 & 51.69 & 2.475 \\
\hline 13 & 0 & 0 & $\sqrt{2}$ & 0.599 & 21.4 & 1.836 & 0.190 & 131.01 & 1.410 \\
\hline 14 & 0 & 0 & $-\sqrt{2}$ & 0.227 & 16.5 & 0.583 & 0.295 & 41.62 & 2.187 \\
\hline 15 & 0 & 0 & 0 & 0.315 & 13.7 & 1.035 & 0.277 & 73.85 & 2.054 \\
\hline 16 & 0 & 0 & 0 & 0.206 & 10.4 & 1.035 & 0.239 & 73.85 & 1.769 \\
\hline 17 & 0 & 0 & 0 & 0.337 & 14.2 & 1.035 & 0.287 & 73.85 & 2.124 \\
\hline 18 & 0 & 0 & 0 & 0.294 & 13.1 & 1.035 & 0.271 & 73.85 & 2.005 \\
\hline 19 & $\sqrt{2}$ & 0 & 0 & 0.447 & 15.4 & 1.035 & 0.350 & 228.43 & 2.592 \\
\hline 20 & $-\sqrt{2}$ & 0 & 0 & 0.355 & 11.3 & 1.035 & 0.379 & 23.87 & 2.805 \\
\hline 21 & 0 & $\sqrt{2}$ & 0 & 0.553 & 13.9 & 1.035 & 0.480 & 104.97 & 2.502 \\
\hline 22 & 0 & $-\sqrt{2}$ & 0 & 0.339 & 17.4 & 1.035 & 0.235 & 51.69 & 2.490 \\
\hline 23 & 0 & 0 & $\sqrt{2}$ & 0.525 & 13.9 & 1.836 & 0.257 & 131.01 & 1.901 \\
\hline 24 & 0 & 0 & $-\sqrt{2}$ & 0.239 & 17.5 & 0.583 & 0.293 & 41.62 & 2.167 \\
\hline
\end{tabular}

For determining S/N ratios there are three characteristics lower the better, higher the better, nominal the better. For increasing the production rate higher the better is good for the case of MRR and lower the better is good for the case of chip reduction coefficient.

\section{THEORETICAL ANALYSIS}

The second order equation for chip reduction coefficient and MRR was found by using design of experiments.

$Y($ Chip reduction coefficient $)=2.1396-0.0447 X_{1}-0.0068 X_{2}-0.1085 X_{3}+0.0771 X_{1}^{2}+0.1322 X_{2}^{2}-0.1870 X_{3}^{2}-0.1160 X_{1} X_{2}-$ $0.1531 X_{1} X_{3}+0.1553 X_{2} X_{3}$

$Y(M R R)=73.2725+72.6155 X_{1}+23.1588 X_{2}+36.9623 X_{3}+26.6275 X_{1}^{2}+2.7175 X_{2}^{2}+6.7100 X^{2}+18.2275 X_{1} X_{2}+28.0725 X_{1} X_{3}+10$ $.5800 X_{2} X_{3}$

The above two equations show the DOE models for chip reduction coefficient and MRR. DOE models were interpreted in the form of plots. These plots show the variation of chip reduction coefficient and MRR with respect to cutting velocity, feed and depth of cut. In fig. 2 at constant speed code 0 , it is observed that with increase in feed MRR increases similarly with increase in doc MRR increases. In fig. 2 when the speed code is increased to 1 similar kind of observation is noted hence with increase in feed, speed, doc MRR increases. 

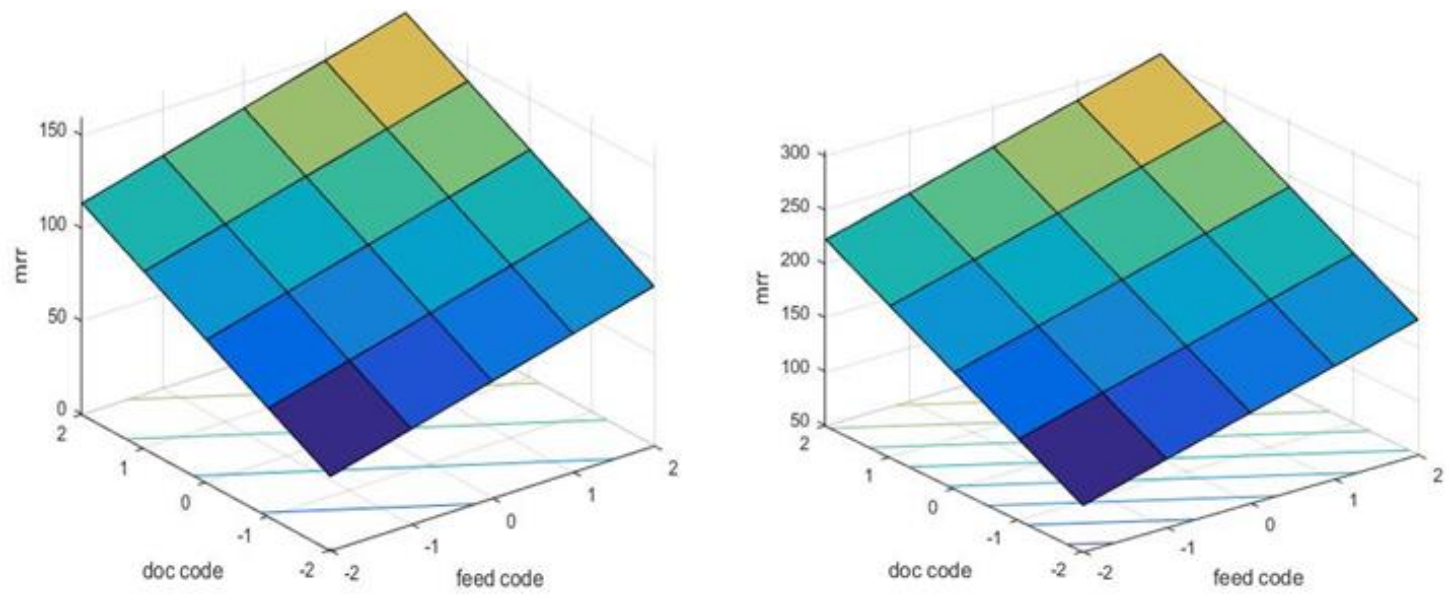

Figure 2: Variation of MRR with Feed Code and Depth of Cut at Different Speed Code. Speed Code 0 (Left) and Speed Code 1 (Right).

The variation of chip reduction coefficient with feed and depth of cut at different speed codes are shown in Fig. 3. It is observed that at constant speed code 0 with increase in feed chip reduction coefficient also increases. This is mainly because of predominating austenitic retention effect at higher feed. However, variation with respect to doc is different. It is observed that with increase in doc, chip reduction coefficient reduces. This is because of work hardening effect.

Similar case is seen for higher speed code 1, but the increase in chip reduction coefficient with respect to feed has higher value at low speed because of austenitic retention effect. The value of chip reduction coefficient is more with respect to doc at lower speed, this is also because of the austenitic retention effect is at lower cutting speed.
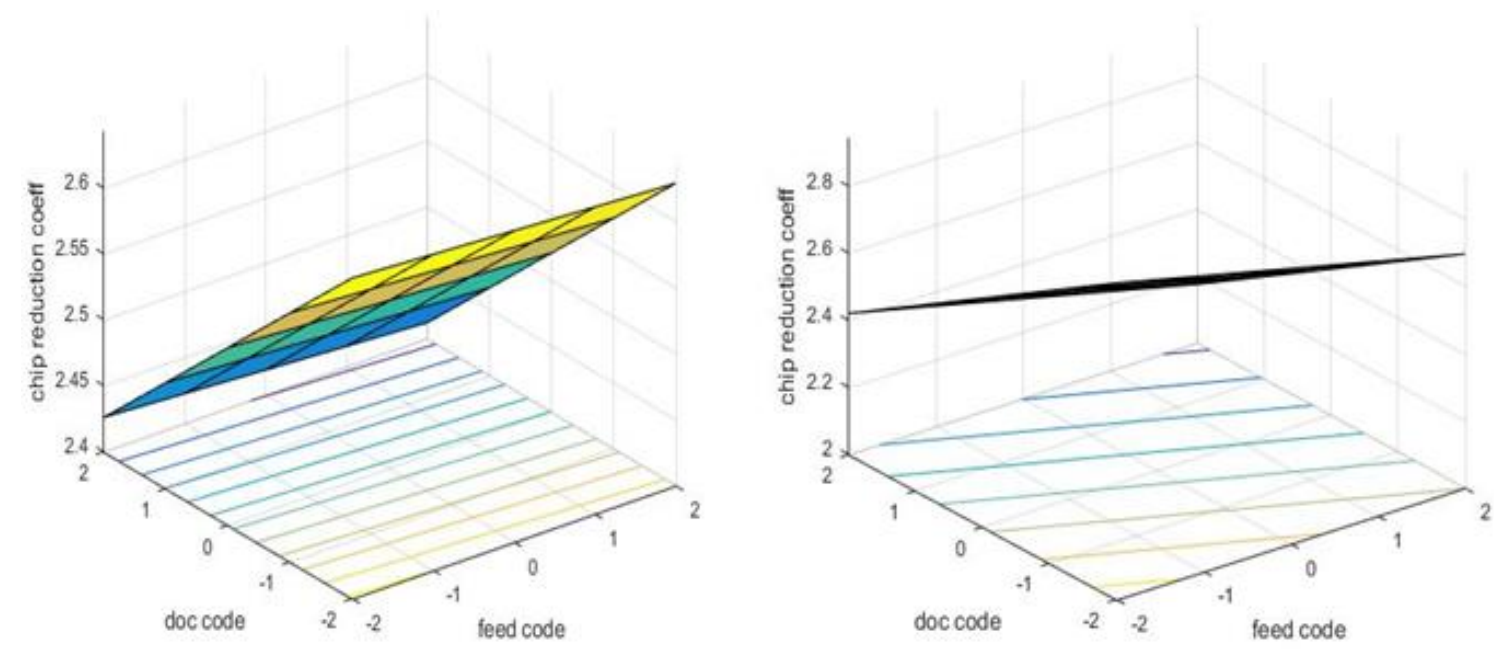

Figure 3: Variation of Chip Reduction Coefficient with Doc and Feed Code at Different Speed Code. Speed Code 0 (Left) and Speed Code 1 (Right).

Table 4: Parameters used for Theoretical Analysis Purpose

\begin{tabular}{|l|c|c|c|}
\hline \multicolumn{1}{|c|}{ Coding } & $-\sqrt{\mathbf{2}}$ & $\mathbf{0}$ & $\sqrt{\mathbf{2}}$ \\
\hline Speed $(\mathrm{mm} / \mathrm{min})$ & 10.23 & 31.65 & 97.9 \\
\hline Feed $(\mathrm{mm} / \mathrm{rev})$ & 0.01 & 0.14 & 0.20 \\
\hline DOC $(\mathrm{mm})$ & 0.56 & 1 & 1.77 \\
\hline
\end{tabular}

Orthogonal array for chip reduction coefficient and MRR was made by using parameters from table and the S/N ratios for chip reduction coefficient and MRR was made by using Taguchi analysis. The normalized values of S/N ratio were used to obtain Multi performance Characteristic Index through MATLAB software using FIS. 
Table 5: Taguchi Analysis Results

\begin{tabular}{|c|c|c|c|c|c|c|c|c|c|}
\hline $\begin{array}{c}\text { Sr } \\
\text { No }\end{array}$ & $\boldsymbol{v}$ & $\boldsymbol{f}$ & $\boldsymbol{d}$ & $\begin{array}{c}\mathbf{M R R} \\
\mathbf{\mathbf { m m } ^ { 3 } / \mathbf { s }}\end{array}$ & $\begin{array}{c}\text { Chip } \\
\text { reduction } \\
\text { coefficient }(\boldsymbol{\zeta})\end{array}$ & $\begin{array}{c}\text { S/N ratio } \\
\text { of MRR } \\
(\boldsymbol{d} \boldsymbol{B})\end{array}$ & $\begin{array}{c}\text { S/N ratio of Chip } \\
\text { reduction } \\
\text { coefficient }(\boldsymbol{d B})\end{array}$ & $\begin{array}{c}\text { Normalized } \\
\text { S/N ratio of } \\
\text { MRR }\end{array}$ & $\begin{array}{c}\text { Normalized S/N } \\
\text { ratio of Chip } \\
\text { reduction } \\
\text { coefficient }\end{array}$ \\
\hline 1 & 1 & 1 & 1 & 71.424 & 2.178 & 37.076 & -6.764 & 0.431 & 0.253 \\
\hline 2 & 1 & 2 & 2 & 23.833 & 2.357 & 27.543 & -7.447 & 0 & 0.058 \\
\hline 3 & 1 & 3 & 3 & 56.272 & 2.316 & 35.005 & -7.297 & 0.337 & 0.101 \\
\hline 4 & 2 & 1 & 2 & 45.956 & 2.413 & 33.246 & -7.653 & 0.257 & 0 \\
\hline 5 & 2 & 2 & 3 & 138.965 & 1.612 & 42.858 & -4.148 & 0.692 & 1 \\
\hline 6 & 2 & 3 & 1 & 51.446 & 2.173 & 34.227 & -6.742 & 0.302 & 0.259 \\
\hline 7 & 3 & 1 & 3 & 266.127 & 2.208 & 48.501 & -6.882 & 0.947 & 0.219 \\
\hline 8 & 3 & 2 & 1 & 134.223 & 2.010 & 42.556 & -6.064 & 0.679 & 0.453 \\
\hline 9 & 3 & 3 & 2 & 303.862 & 2.253 & 49.653 & -7.056 & 1 & 0.170 \\
\hline
\end{tabular}

\section{FUZZY INFERENCE SYSTEM RESULT}

Multi Performance Characteristic Index (MPCI) was obtained by using fuzzy logic. Fuzzy inference system using MATLAB software was used to obtain MPCI. The inputs given were chip reduction coefficient and MRR and MPCI obtained as output. The input and output functions were plotted in terms of triangular member function, rules were framed in fuzzy and with the help of these rules the inputs were simulated to get the surface which shows the variation of MPCI values with respect to chip reduction coefficient and MRR.

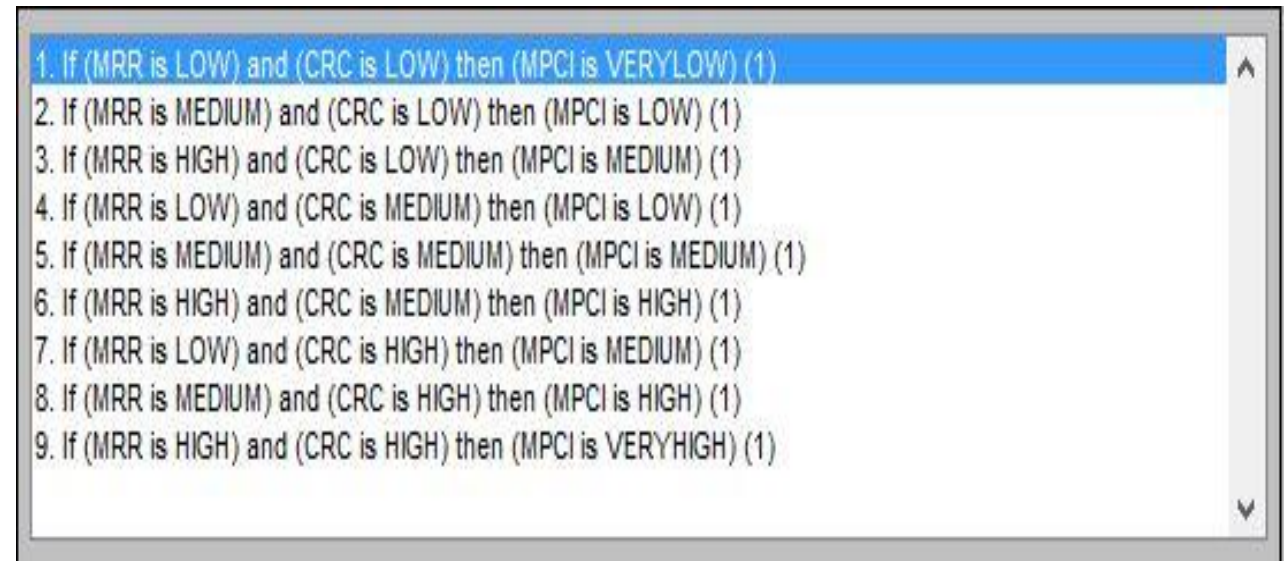

Figure 4: Rules Framed in Fuzzy Inference System.

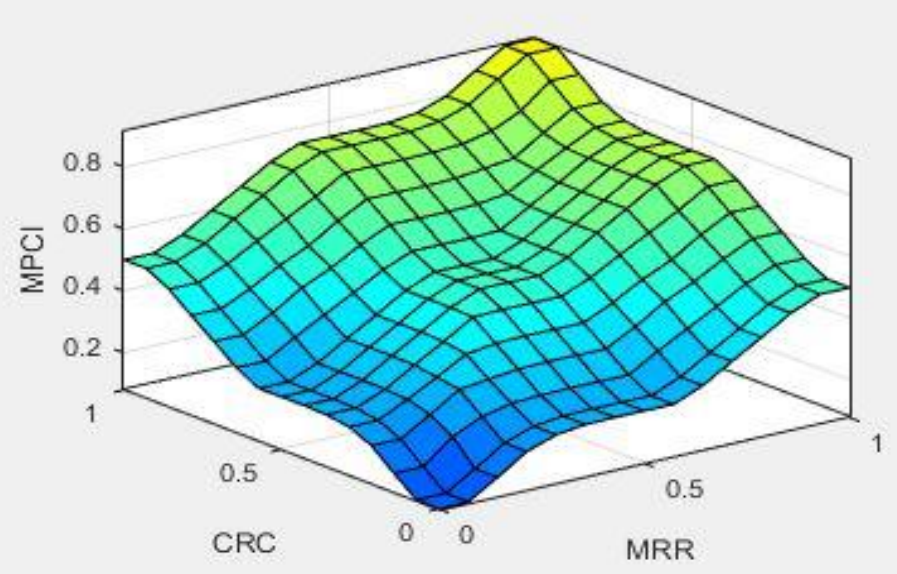

Figure 5: Surface Showing Variation of MPCI with MRR and Chip Reduction Coefficient. 
Further analysis was done with MPCI values to get mean response table as shown in table VII

Table 6: MPCI Values from Fuzzy Inference System

\begin{tabular}{|c|c|c|}
\hline Sr No & MPCI & SN ratio of MPCI $(\boldsymbol{d B})$ \\
\hline 1 & 0.378 & -8.450 \\
\hline 2 & 0.0819 & -21.734 \\
\hline 3 & 0.247 & -12.146 \\
\hline 4 & 0.228 & -12.841 \\
\hline 5 & 0.759 & -2.395 \\
\hline 6 & 0.37 & -8.635 \\
\hline 7 & 0.601 & -4.422 \\
\hline 8 & 0.569 & -4.897 \\
\hline 9 & 0.562 & -5.005 \\
\hline
\end{tabular}

Table 7: Mean Response Table

\begin{tabular}{|c|c|c|c|}
\hline Levels & $\boldsymbol{v}$ & $\boldsymbol{f}$ & $\boldsymbol{d}$ \\
\hline 1 & -14.110 & -8.571 & -7.327 \\
\hline 2 & -7.957 & -9.675 & -13.193 \\
\hline 3 & -4.775 & -8.595 & -6.321 \\
\hline Delta (max-min) Rank & 1 & 3 & 2 \\
\hline
\end{tabular}

From the mean response table, the effect of speed is more followed by depth of cut and feed.

Rank assigned as

Speed $=1$

Doc $=2$

Feed $=3$

The optimality condition is finally attained at (2 23 ).

\section{CONCLUSIONS}

- $\quad$ MRR increases with speed, feed and doc

- Chip reduction coefficient increases with increase in feed.

- Chip reduction coefficient decreases with increase in doc.

- With respect to MPCI consideration, speed effect is more influential in comparison to doc and feed.

- Machining on austenitic stainless steel (316L) is found to be influenced by austenitic retention effect and transformational effect during the machining work.

\section{ACKNOWLEDGEMENT}

Authors are grateful to National Institute of Technology Silchar for providing financial assistance to carry out this research work.

\section{REFERENCES}

1. DasS.r, Kuma A, Dhupal D, MohapatraS.k, 9 nov 2013, "Optimization of surface roughness in hard turning of AISI 4340 steel using coated carbide inserts", international Journal of information and computation technology, 3, 871-880 
2. M. Kaladhar, Ch.Srinivasa Rao, Kandukuri Narayana Rao. "Optimization of process parameters in turning of AISI 202 austenitic stainless steel”.'Research gate (2010).

3. Duhan, R. A. V. I., and S. U. R. A. J. Choudhary. "Effect of different fluxes on hardness and microstructure of SS 304 in GTAW welding." International Journal of Mechanical Engineering 3.4 (2014): 1-8.

4. Philip SelvarajDirviyam, ChandramohanPalanisamy. "Optimization of surface roughness of AISI 304 austenitic stainless steel in dry turning operation using Taguchi design method".Journal of Engineering Science and Technology. September (2010).

5. M. Kaladhar, K. VenkataSubbaiah, Ch. Srinivasa Rao. "Determination of Optimum Process Parameters during turning of AISI 304 Austenitic Stainless Steels using Taguchi method and ANOVA”. International Journal of Lean Thinking Volume 3, Issue 1 (June 2012).

6. Erfan, O. S. A. M. A., et al. "Erosion-corrosion behavior of AA 6066 aluminum alloy." Ijme 3 (2014): 15-24.

7. IhsanKorkut, Mustafa Kasap, Ibrahim Ciftci, UlviSeker. "Determination of optimum cutting parameters during machining of AISI 304 austenitic stainless steel’.'Materials and Design 25 (2004) 303-305.

8. Saini, Parveen, and Suraj Choudhary. "Analysis of Machining Parameters for the Optimization of Surface Roughness of Stainless Steel AISI 202 in CNC Face Milling Process. "International Journal of Mechanical Engineering (IJME) 2. 3, July 2013, 27-34

9. [6] Atul P. Kulkarni, Girish G. Joshi, Vikas G. Sargade. "Dry turning of AISI 304 austenitic stainless steel using ALTiCrN coated insert produced by HPPMS technique”. Procedia Engineering 64 (2013 ) 737 - 746.

10. Erfan, O. S. A. M. A., et al. "Erosion-corrosion behavior of AA 6066 aluminum alloy." Ijme 3 (2014): 15-24. 